\title{
MAA Awards Given in San Antonio
}

At the Joint Mathematics Meetings in San Antonio, Texas, in January 2015, the Mathematical Association of America awarded several prizes.

\section{Gung and Hu Award for Distinguished Service}

The Yueh-Gin Gung and Dr. Charles Y. Hu Award for Distinguished Service to Mathematics is the most prestigious award given by the MAA. It honors distinguished contributions to mathematics and mathematical education in one particular aspect or many, whether in a short period or over a career.

The 2015 Gung and Hu Award was presented to W. JAMES LEWIS, Aaron Douglas Professor of Mathematics and director of the Center for Science, Mathematics, and Computer Education at the University of Nebraska-Lincoln, for his outstanding contributions to the mathematics education of teachers, for his leadership in the mathematics profession and in academia at all levels, for his work increasing the visibility and participation of women in mathematics, for his exemplary work serving the state of Nebraska, and especially for his vision and ability to bring together diverse stakeholders in support of positive change in mathematics.

Over the past two decades Lewis has profoundly changed not only mathematics education but also the way mathematicians think about mathematics education. In the late 1990s, the Conference Board of the Mathematical Sciences (CBMS) decided that the mathematics community, represented by a variety of mathematics organizations, should make recommendations about how K-12 mathematics teachers should be educated. Lewis took on two major roles during this time: chair of the steering committee that

DOI: http://dx.doi.org/10.1090/noti1244 produced The Mathematical Education of Teachers, published jointly by the MAA and the AMS as part of the CBMS Issues in Mathematics Education series, and cochair of the National Academy of Sciences committee that wrote Educating Teachers of Science, Mathematics and Technology: New Practices for the New Millennium (2000). The Mathematical Education of Teachers (MET), published in 2001, expounded what ought to be the principles behind the preparation of high-quality mathematics teachers at the elementary, middle, and high school levels. It was unwavering in its strong advice but also recognized practical limitations. A masterful blend of common sense, research-based recommendations, and sensible commentary, it changed the way mathematicians and educators interact when talking about teacher preparation.

Lewis cochaired the 2001 National Summit on the Mathematical Education of Teachers and later the advisory board for the second "national summit" focusing on minority-serving institutions. He continued to urge the involvement of mathematicians in the mathematical education of teachers. He served as Nebraska State Coordinator for the MAA's PMET grant, as chair of the organizing committee for the 2007 and 2014 Mathematical Sciences Research Institute (MSRI) Critical Issues Workshops and of the organizing committee for the 2008 MSRI workshop, and as chair of the organizing committee for the 2011 CBMS forum Teaching Teachers in the Era of the Common Core. Between 2005 and 2010 he was one of two mathematicians who served on the National Research Council (NRC) committee that produced the report Preparing Teachers: Building Evidence for Sound Policy. He also chaired the writing team that produced the updated document The Mathematical Education of Teachers II (2012). The creation of this report was again a collaborative effort from a diverse group of experts given 
cohesion through Lewis's leadership and vision. It too will have a lasting impact on our community.

Lewis's mathematics education work at the national level has not been restricted to the mathematical education of teachers. He was a member of the AMS task force that produced Towards Excellence: Leading a Doctoral Mathematics Department in the 21st Century (1999). Research mathematics departments that have adopted the philosophy advocated in Towards Excellence have produced $\mathrm{PhD}$ graduates who are strong researchers and well-rounded stewards of the profession.

In K-12 mathematics education, Lewis was one of the authors of the US Department of Education's What Works Clearinghouse practice guide Developing Effective Fractions Instruction for Kindergarten through Eighth Grade. He was also a member of the National Council of Teachers of Mathematics (NCTM) committee that produced the documents Focus in Grade 6: Teaching with Curriculum Focal Points and Focus in Grades 7 and 8: Teaching with Curriculum Focal Points.

Lewis was chair of the MAA Coordinating Council on Education, the AMS Committee on Science Policy, and the AMS Task Force on the First-Year College Mathematics Experience. He has served as a member of the AMS Committee on Education, the US Department of Education's Mathematics Education Study Panel, the NRC's Mathematical Sciences Education Board, the National Science Foundation's (NSF) Education and Human Resources Directorate Advisory Board, NSF's Mathematics Education Portfolio Review Committee, MSRI's Education Advisory Committee, Arizona's Institute for Mathematics and Education, and Math for America's Board of Directors. He has served as chair of the CBMS and on the advisory board for several NSFfunded projects. Currently, he is a member of the planning committee for the Association of Public and Land Grant Universities' Mathematics Teacher Education Partnership.

Lewis has had a profound effect on the shape of K-16 education at the University of NebraskaLincoln (UNL) and across the state of Nebraska. His work with pre-service teachers started with the creation (in close collaboration with Ruth Heaton from UNL's Department of Teaching, Learning and Teacher Education) of the Mathematics Semester, a ten-hour integrated experience involving courses in math content, pedagogy, and field experience that is now part of the education of all future elementary teachers at UNL. With financial support from both internal and external sources, he has since created an impressive collection of professional development opportunities for in-service teachers over the past ten years. During this time, he has been the principal investigator for two NSF Math Science Partnerships, Math in the Middle and NebraskaMATH, and for an NSF Robert Noyce Scholarship grant, NebraskaNOYCE. The Math in the Middle program enabled 156 teachers to earn master's degrees. NebraskaMATH focuses on teachers at the primary and high school levels; one facet of the program is Primarily Math, which enables teachers to earn K-3 Mathematics Specialists certificates, and another is the New Teacher Network, through which secondary mathematics teachers earn graduate credits and receive mentoring as they begin their teaching careers. In order to have a long-term and lasting impact on teachers, Lewis created the Nebraska Math and Science Summer Institutes, offering graduate-level courses for in-service teachers in a sustainable way, both online and in person across the state.

Lewis has also worked to encourage gender equity and diversity in mathematics. The UNL Department of Mathematics awarded no PhDs to women during the 1980s. Lewis, on becoming chairman in 1988, committed to transforming the environment to one in which talented women would be given the opportunities and support needed to succeed. He led the charge to reexamine the structure of the graduate program, making changes as needed to remove barriers to success and improving the graduate experience for all students. He actively recruited qualified women into the graduate program. Since 1995 the department has awarded 42 percent of its PhDs to women. The department has maintained gender equity in the graduate program, becoming nationally known as one of the most successful departments in the country for mentoring women in the profession. In recognition of this tremendous transformation, the department received a 1998 NSF Presidential Award for Excellence in Science, Math, and Engineering Mentoring. Lewis was individually honored as well with the 1996 UNL Chancellor's Commission on the Status of Women Award and the 1997 Lincoln-Lancaster County Women's Commission Erasmus Correll Award.

Throughout his career, Lewis has been a tireless advocate of the idea that mathematics research and education go hand in hand. During his fifteen-year tenure as department chair at UNL, his department created such enrichment programs for K-12 education as UNL's Math Day, the All Girls/All Math summer camps for high school girls, an NSF-funded Research Experience for Undergraduates (REU) in applied mathematics, and the Nebraska Conference for Undergraduate Women in Mathematics. Partially because of his legacy, the AMS honored the UNL Department of Mathematics with the Society's 2009 Award for an Exemplary Program or Achievement in a Mathematics Department.

\section{Beckenbach Book Prize}

The Beckenbach Book Prize is named for Edwin Beckenbach, a long-time leader in the publications program of the MAA. The prize is intended to 
recognize the author(s) of a distinguished, innovative book published by the MAA and to encourage the writing of such books. The award is not given on a regularly scheduled basis. To be considered for the Beckenbach Prize a book must have been published during the five years preceding the award.

The 2015 prize has been awarded to SETH BrAVER, Puget Sound Community College, for his book Lobachevski Illuminated (MAA Spectrum, 2011).

Mathematicians of all stripes know that the non-Euclidean revolution was a game-changer in nineteenth-century mathematics. But relatively few mathematicians are acquainted with the little book that heralded this revolution, Nikolai Lobachevski's Theory of Parallels (in German, 1840). In Lobachevski Illuminated, Braver gives us a translation of the text, accompanies each of its thirty-seven propositions with an extensive commentary, and places these ideas in their proper historical context. As a result, Braver has done nothing less than give new life to an old masterpiece.

He begins by celebrating Euclid's Elements as "mankind's greatest monument to the power of rational, organized thought." So brilliantly did Euclid develop his geometry and so long did this development dominate the mathematical landscape that "any individual with the impertinence to challenge Euclid's authority was certain to inspire reactions of both incredulity and scorn."

Lobachevski was sufficiently impertinent-and insightful-to do just that. He replaced Euclid's parallel postulate by an alternative to create a geometry so different that he called it "imaginary." By leading us through Lobachevski's text, Braver manages to recreate the excitement and, yes, the unease that nineteenth-century mathematicians must have felt. At the outset he cautions the modern reader, "If you have never left the Euclidean world before, then be forewarned: you are about to embark on a thoroughly disorienting (but strangely exhilarating) journey."

In the book, Braver sets apart Lobachevski's words (in red) from his own running commentary (in black) to flesh out the terse style of the original. In the process, we become familiar, even comfortable, with a new definition of "parallel," with triangles that have no circumscribing circle, with horocycles and horospheres, and with the peculiar trigonometry that arises naturally in the process. It's all there in Lobachevski's own words, augmented by Braver's rich illuminations.

To add a bit of context to the geometrical ideas, the author pauses now and then to discuss the works of predecessors such as Saccheri, Legendre, Gauss, and Clairaut. For instance, the last of these had shown that the parallel postulate holds if and only if a rectangle exists. Braver raises the intriguing question of how "the history of non-Euclidean geometry might have unfolded had Euclid assumed the existence of a rectangle rather than his parallel postulate.... Could the mere assumption that a rectangle exists have provoked Saccheri's struggle to 'free Euclid from every flaw'?"

The reader of Lobachevski Illuminated will encounter a host of such provocative questions, will delve deeply into the history of geometry, and will gain a thorough appreciation of the genius of Nikolai Lobachevski.

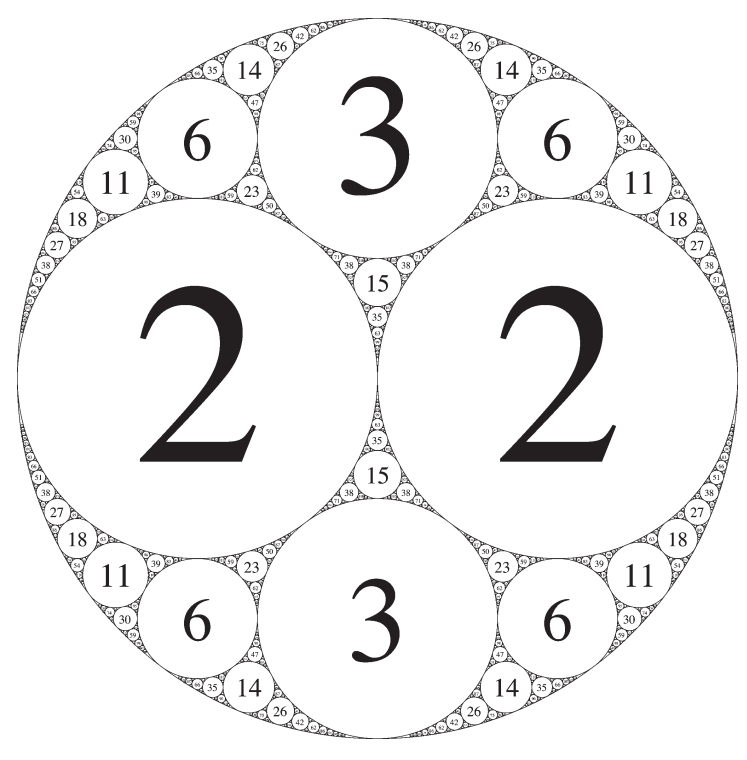

\section{Chauvenet Prize}

The Chauvenet Prize recognizes a member or members of the MAA for the writing of an outstanding expository article. First awarded in 1925, the prize is named for William Chauvenet, who was a professor of mathematics at the United States Naval Academy.

The 2015 Chauvenet Prize was awarded to DANA MACKENZIE for the article "A Tisket, a Tasket, an Apollonian Gasket,” American Scientist 98 (2010), no. $1,10-14$.

Start with three mutually tangent circles, insert a fourth circle tangent to all three, and iterate. If the four circles have curvatures that are integers, then all subsequent curvatures are integers too, and the construction yields an integral Apollonian circle packing. (See image above from Mackenzie's article.)

Writing as a tour guide for the scientifically literate traveler to the world of mathematical research, the author narrates a charming Apollonian journey with waypoints that include classical Greek geometry, correspondence between René Descartes and Princess Elizabeth of Bohemia, Japanese temple problems, the poetry of a Nobel laureate in chemistry, and fractal dimension. During the excursion, the guide muses on cultural differences between 
physicists and mathematicians, computer experimentation as a source of mathematical problems, and creativity as an ingredient in mathematical proof.

Beginning with the first principles, the engaging exposition conducts the reader to the frontiers of mathematical research. The author whets the reader's appetite for further adventures by mentioning some unsolved problems of number theory. This exemplary article appeals to mathematicians and nonmathematicians alike.

Dana Mackenzie received his PhD from Princeton University in 1983 and taught for thirteen years at Duke University and Kenyon College. In 1996 he entered the Science Communication Program at the University of California at Santa Cruz, and since then he has been a freelance journalist, specializing in mathematics while also writing in other sciences. His writing has been published in Scientific American, Science, Discover, New Scientist, Smithsonian, and American Scientist. He has written two books for the general public, including The Universe in Zero Words (Princeton University Press, 2012). He also writes the ongoing series What's Happening in the Mathematical Sciences, published by the American Mathematical Society.

\section{Euler Book Prize}

The Euler Book Prize is given to the author or authors of an outstanding book about mathematics. Mathematical monographs at the undergraduate level, histories, biographies, works of mathematical fiction, and anthologies are among those types of books eligible for the prize. The prize was given for the first time in 2007, the three hundredth anniversary of the birth of Leonhard Euler.

The Euler Prize for 2015 was awarded to EDWARD FRENKEL of the University of California Berkeley for Love and Math: The Heart of Hidden Reality (Basic Books, New York, 2013).

What if you had to take an art class in which you were taught only how to paint a fence? What if you were never shown the paintings of van Gogh and Picasso, were not even told they existed? Alas, this is how math is taught, and so for most of us it becomes the intellectual equivalent of watching paint dry.

In Love and Math, renowned mathematician Edward Frenkel reveals a side of math we've never seen, suffused with all the beauty and elegance of a work of art. In this heartfelt and passionate book, Frenkel shows that mathematics, far from occupying a specialist niche, goes to the heart of all matter, uniting us across cultures, time, and space. Love and Math tells two intertwined stories: of the wonders of mathematics and of one young man's journey learning and living it. Having braved a discriminatory educational system to become one of the twenty-first century's leading mathematicians, Frenkel now works on one of the biggest ideas to come out of mathematics in the last fifty years: the Langlands Program. Considered by many to be a Grand Unified Theory of Mathematics, the Langlands Program enables researchers to translate findings from one field to another so that they can solve problems, such as Fermat's Last Theorem, that had seemed intractable before. At its core, Love and Math is a story about accessing a new way of thinking which can enrich our lives and empower us to better understand the world and our place in it. It is an invitation to discover the magic hidden universe of mathematics. It was a New York Times bestseller, was named one of the best books of 2013 by both Amazon and iBooks, and is being translated into fourteen languages.

Edward Frenkel is a professor of mathematics at the University of California, Berkeley, which he joined in 1997 after being on the faculty at Harvard University. He is a member of the American Academy of Arts and Sciences, a Fellow of the American Mathematical Society, and the winner of the Hermann Weyl Prize in Mathematical Physics. Frenkel has also coproduced, codirected, and played the lead in the film Rites of Love and Math (Sycamore Films, 2010).

\section{Haimo Awards for Teaching}

The Deborah and Franklin Tepper Haimo Awards for Distinguished College or University Teaching of Mathematics were established in 1991. These awards honor college or university teachers who have been widely recognized as extraordinarily successful and whose teaching effectiveness has been shown to have had influence beyond their own institutions.

The 2015 Haimo Awards were presented to BRIAN HOPKINS (Saint Peter's University), JUDITH Covington (Louisiana State University-Shreveport), and SHAHRIAR SHAHRIARI (Pomona College). The following is taken from their prize citations and biographical information.

Brian Hopkins is described as a master teacher with a genuine desire to see all of his students succeed. With a knack for posing problems and the ability to create an atmosphere of mutual respect and exploration in his classroom, Hopkins's courses are student centered, featuring carefully chosen problems that lead students to discover mathematics for themselves. Discovery happens at all levels, from elementary counting problems in finite mathematics to complex applications of modern mathematics in symbolic dynamics, phylogenic trees, or the mathematics of search engines. In many of his upper-division courses, Hopkins also exposes mathematics majors to the nature of mathematical research by having his students read contemporary research articles. Students praise Hopkins for his passion for mathematics, his patient and giving manner, his challenging coursework, and his unique teaching style. 
At Saint Peter's University, Hopkins has been instrumental in creating three new courses for the math department: the Mathematics Technology Laboratory, where sophomore majors learn Mathematica and LTEX; an undergraduate research course in which students outside the university's honors program can do research; and the Senior Seminar in Mathematics, which serves as a capstone experience for mathematics majors. He has also helped the department develop a threecourse graduate-level track for middle school teachers to meet new certification requirements. His teaching in this three-course sequence is informed by his many years of working with teachers in professional development.

Hopkins has been working closely with fifty to sixty teachers each year since 1998 as a staff member with the Institute for Advanced Study's Park City Mathematics Institute (IAS/PCMI). Participants ranging from elementary to high school mathematics teachers voice appreciation for Hopkins's ability to connect with such a diverse group in a meaningful way, enhancing teacher instruction by improving mathematical knowledge and reinvigorating the teachers' interest in the field. He has had a similar impact on hundreds of Colorado and New Jersey middle school and high school teachers in his role as facilitator for both the Pike's Peak MathTeachers Circle Summer Academy (2008-12) and the Institute for New Jersey Mathematics Teachers since 2002.

Hopkins is an active researcher with interests in combinatorial number theory and mathematics applied to social science, including game theory and fair division. Over the years Brian has led undergraduate research with over thirty students at Saint Peter's University, including two Research Experiences for Undergraduates (REU) programs for which he obtained external funding. This work has led to more than twenty student presentations and posters at local and national conferences.

Saint Peter's University students have recognized Hopkins's talents by awarding him the Francis A. Varrichio Award for Excellence in Teaching in 2004, 2007, and 2012. Hopkins also received the New Jersey MAA Section Award for Distinguished College or University Teaching of Mathematics in 2011. He won the George Pólya Award in 2005 for an article coauthored with Robin Wilson titled "The truth about Königsberg," College Math. J. 35 (2004), no. 3, 198-207), and in January of 2014 Hopkins started his new role as editor of that MAA journal.

Hopkins is a professor of mathematics at Saint Peter's University in Jersey City, New Jersey. He received his $\mathrm{PhD}$ from the University of Washington. He has also taught at Seattle University, Harvey Mudd College, and New York University (in the politics department). Another major aspect of his teaching has been facilitating content-based professional development for K-12 mathematics teachers in New Jersey, Colorado, and Washington State and reaching throughout the country with the IAS/PCMI Summer School Teachers Program. Hopkins edited the 2009 Resources for Teaching Discrete Mathematics (MAA, 2001) and coedited Martin Gardner in the Twenty-First Century (MAA, 2012). He has published research papers dealing with integer partitions, combinatorial proofs, graph theory, Rado numbers, history of mathematics, game theory, and fair division.

Judith Covington is a talented and passionate teacher devoted to mentoring current and future teachers. Her teaching is characterized as well rounded, making use of a healthy balance of traditional and innovative teaching methods. Her students describe her as patient, accessible, dedicated, helpful, and knowledgeable. Her colleagues admire the energy and expertise she brings to the classroom and to the teachers she mentors. Covington's ability to reach and inspire future and current teachers is a special gift.

Covington has received several large grants to develop teacher-preparation programs in Louisiana. In the late 1990s she designed two new innovative courses for future elementary teachers and an intensive summer workshop for middle school teachers. The courses remain a requirement for students in elementary education today. Louisiana State University-Shreveport has been recognized by the state of Louisiana for its exceptional preparation of elementary education graduates in mathematics and the sciences. Covington also designed a highly successful inquiry-based college geometry course for pre-service teachers.

In 2010 Professor Covington founded the North Louisiana Math Teachers Circle (NLMTC), involving teachers from northern Louisiana in monthly problem-solving sessions. Pre-service and in-service teachers appreciate Covington for fostering a love of problem solving and a passion for mathematics. Her enthusiasm for mathematics and her dedication to her students is clearly making a difference in her local community.

Covington has also had an extraordinary impact in teaching at the national level. A member of the first Project NExT class, she has served on the Project NExT leadership team for almost twenty years, having a direct and profound impact on the professional careers of over 1,400 new faculty members who are themselves shaping mathematics education across the nation. She runs the Project NExT NExTEd email list, providing a vibrant forum for young faculty specializing in mathematics education, and she teaches a Project NExT minicourse titled "Preparing Teachers". As her colleagues describe, Covington's knowledge, energy, and ability to work with people make her the perfect role model for teachers of all levels.

Covington's success in teaching has been recognized at the university, local, and state levels. 
In 2004 she was awarded the LSU-Shreveport Elmer and Barbara Simon Distinguished Teaching Professorship, and in 2012 she received both the Champions for Mathematics Education Award from the local National Council of Teachers mathematics affiliate and the Louisiana-Mississippi MAA Section's Distinguished Teaching Award.

Covington received her $\mathrm{PhD}$ from the University of Louisiana-Lafayette in 1993. She accepted her first job at LSU-Shreveport upon graduation and continues to serve there as a professor of mathematics. Early in her career she developed a passion for working with future teachers, and the majority of her teaching load is courses for future elementary teachers. She has provided professional development opportunities for teachers at all levels. In 2010 she founded the North Louisiana Math Teachers' Circle, which is still active today. Each month about twenty-five middle school teachers gather to work on interesting problems in mathematics.

Shahriar Shahriari is a gifted and accomplished teacher, recognized for the significant time he spends mentoring students. Described as both passionate and inspirational, he has the ability to engage students of all levels, and he makes concerted efforts to reach out to students from underrepresented groups. Students, alumni, and colleagues are particularly appreciative of the supportive learning communities Shahriari creates by intentionally getting students to work collaboratively in groups. These learning communities have empowered students to become resourceful and self-reliant. Students describe their experience working with Shahriari as challenging, transformational, and deeply rewarding.

At Pomona College, Shahriari designed a widely popular and challenging Honors Calculus II course that uses the prime number theorem as a unifying theme for the standard calculus curriculum, covering convergence, differentiation, and integration. Shahriari teaches this course using hands-on experimentation, and his colleagues report that students "clamber over themselves to engage with it." As one colleague describes, the course "proceeds like a collection of seemingly independent short stories whose thematic commonalities slowly, but surely and excitingly, come into relief as a beautiful and connected theory." Shahriari teaches at a high level of sophistication, but he organizes the material in manageable pieces. The notes and problem sets for the course were ultimately published by the AMS in the form of a textbook titled Approximately Calculus, a book that won the American Library Association's Choice Award for Outstanding Academic Title in 2007.

At Pomona, Shahriari has won the Wig Distinguished Professor Award for Excellence in Teaching four times. Recipients of the Wig Award are elected by the junior and senior classes in recognition of exceptional teaching and mentorship, as well as service to the college and community. Shahriari also cofounded the Pomona Academy for Youth Success (PAYS), a summer program targeting high school students from traditionally underrepresented groups and designed to mentor students on all things related to college admission and college life. In nine years, it has graduated two hundred twenty students, all of whom have been accepted at four-year institutions. Shahriari was also the cofounder of an undergraduate research seminar in the mathematics department at Pomona, and he has published peer-reviewed research articles with twenty-four student coauthors.

Shahriari is the William Polk Russell Professor of Mathematics at Pomona College, where he has been since 1989. He received his $\mathrm{PhD}$ from the University of Wisconsin-Madison, where he was a student of Marty Isaacs. His main research interests are combinatorics of posets and extremal combinatorics. He serves on the editorial board of Order, was a cowinner of MAA's Carl B. Allendoerfer Award in 1998, and received the 2014 MAA Southern California-Nevada Section Teaching Award. He coteaches Research Circle, a class in which the sole aim is to work on an open research problem, and he emphasizes collaboration and student discovery in all of his classes.

\section{-MAA announcements}

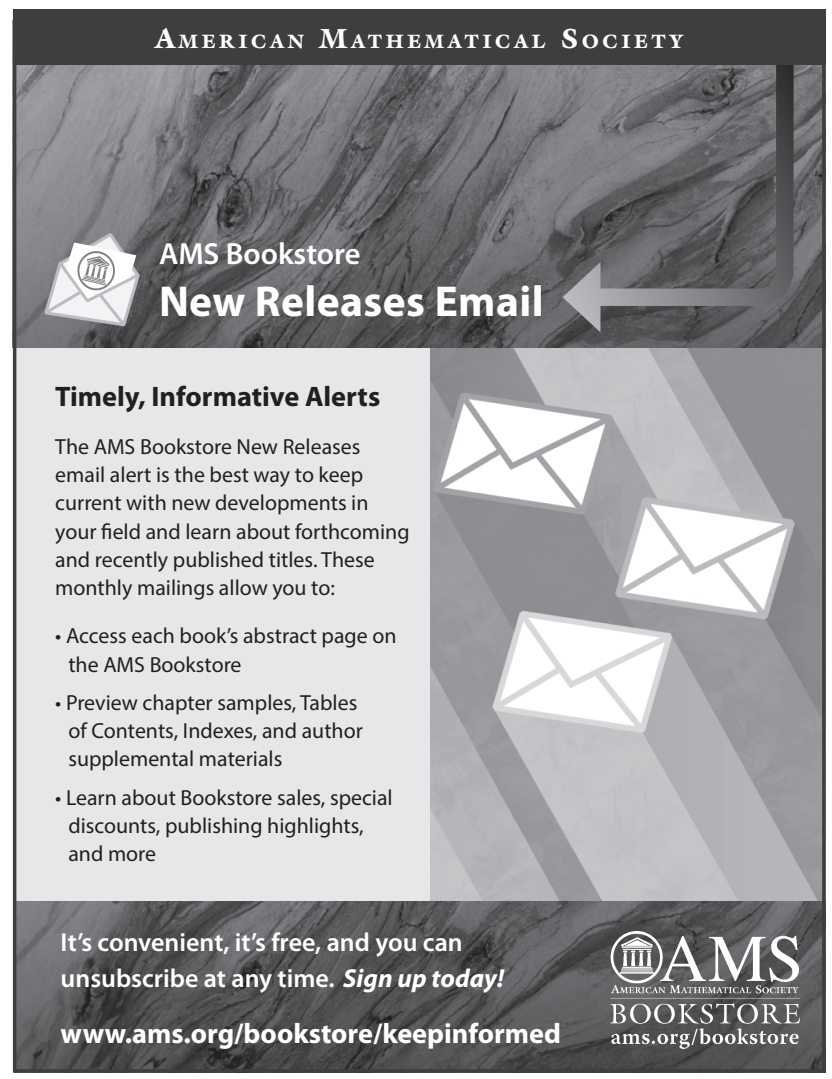

